\title{
O PAPEL DA SUPERVISÃo NA FORMAÇÃO DE TERAPEUTAS COMPORTAMENTAIS: ESTUDO DE CASO
}

\author{
Raquel Martins Sartori \\ Mestre em Educação Especial pela UFSCar. Especialista em Terapia Comportamental por \\ Contingências pelo ITCR-Campinas. Coordenadora do curso de Psicologia do Centro Universitário \\ de Votuporanga. Professora nos cursos de Graduação da UNIFEV.
}

\begin{abstract}
Resumo
O processo terapêutico requer do terapeuta habilidades que vão além de conhecimentos teóricos e técnicas, sendo a relação terapêutica uma variável imprescindível para o sucesso da psicoterapia comportamental. A supervisão de atendimentos clínicos é um recurso pedagógico fundamental para o desenvolvimento de habilidades do futuro terapeuta, bem como, para aumentar as condições de oferta de um atendimento psicoterapêutico mais adequado ao cliente. O presente artigo relata uma experiência de supervisão em que o primeiro cliente de uma terapeuta em formação apresentava padrões comportamentais de agressividade. O padrão do cliente produzia comportamentos e sentimentos na terapeuta que dificultavam o progresso e o sucesso terapêutico. A supervisão ocupou assim um papel de analisar e modelar comportamentos da terapeuta como estratégia para aumentar as chances de sucesso do caso. Em resultado às estratégias adotadas em supervisão, houve mudanças no padrão da interação da terapeuta em formação com seu cliente e avanços no caso.

Palavras-chave: supervisão; formação de terapeutas; habilidades terapêuticas.
\end{abstract}

\section{THE ROLE OF SUPERVISION IN THE TRAINING OF BEHAVIOR THERAPISTS: CASE STUDY}

\begin{abstract}
The therapeutic process therapist requires skills that go beyond the theoretical and technical knowledge, the therapeutic relationship is a prerequisite for the success of behavioral psychotherapy variable. Supervision of clinical care is a fundamental skill development of the future therapist educational resource as well as to increase the supply conditions of a more appropriate psychotherapeutic customer service. The article reports on supervisory experience in the first client of a therapist in training showed behavioral patterns of aggression. The default client produced in therapist behaviors and feelings that hindered progress and therapeutic success. Supervision thus occupied a role in analyzing and modeling the behavior therapist as a strategy to increase the chances of success of the case. As a result of the strategies adopted in supervision, there were changes in the pattern of interaction between therapist and client training with his progress in the case.
\end{abstract}

Keywords: supervision; training of therapists; therapeutic skills. 


\title{
EL PAPEL DE LA SUPERVISIÓN EN LA FORMACIÓN DE LOS TERAPEUTAS DE LA CONDUCTA: ESTUDIO DE CASO
}

\begin{abstract}
Resumen
El proceso terapéutico requiere de habilidades que van más allá del conocimiento teórico y técnico, la relación terapéutica es un requisito previo para el éxito de la variable de la psicoterapia conductual. Supervisión de la atención clínica es un desarrollo de la habilidad fundamental del futuro recurso educativo terapeuta, así como para aumentar las condiciones de la oferta de un servicio de atención psicoterapéutica más apropiado. El artículo informa sobre la experiencia de supervisión en el primer cliente de un terapeuta en el entrenamiento mostraron patrones de comportamiento de la agresión. El cliente predeterminado produce en los comportamientos y sentimientos del terapeuta que obstaculizaron el progreso y el éxito terapéutico. Así Supervisión ocupó un papel en el análisis y modelado de la terapeuta de la conducta como una estrategia para aumentar las posibilidades de éxito del caso. Como resultado de las estrategias adoptadas en materia de supervisión, se produjeron cambios en el patrón de interacción entre el terapeuta y capacitación de los clientes con su progreso en el caso.
\end{abstract}

Palabras clave: supervisión; formación de los terapeutas; habilidades terapéuticas.

\section{INTRODUÇÃO}

A terapia comportamental tem por premissa desenvolver habilidades para que o cliente aprenda a manejar de forma mais efetiva as contingências a que está exposto. Nesse sentido, há a expectativa de que durante o processo psicoterapêutico, o cliente aprenda a lidar com suas condições de vida de forma a aumentar seu acesso a reforçadores, que garantem sentimentos positivos e amenos e minimizar as contingências aversivas, que geram sofrimento, razão pela busca de ajuda psicoterapêutica.

O sucesso do processo psicoterapêutico tem sido frequentemente vinculado à qualidade da relação terapêutica (Meyer e Vermes, 2001). Negligenciada pelos analistas do comportamento até meados da década de 80 , as pesquisas em psicoterapia comportamental ocupavam-se até então em investigar fatores específicos da terapia comportamental, como técnicas e procedimentos operantes (Braga e Vandenberghe, 2006; Silveira e Kerbauy, 2000). A análise de fatores inespecíficos, como as variáveis relativas ao terapeuta e à relação terapêutica, ganhou maior destaque a partir da obra Kohlemberg e Tsai em 1987, conforme Braga e Vandenberghe (2006). A partir dessa proposta, o alvo de análise passou a ser não apenas o comportamento do cliente, mas também o comportamento do terapeuta, por compreender que seus próprios comportamentos são variáveis de controle sobre o comportamento do cliente (Braga e Vandenberghe, 2006; Velasco e Cirino, 2002). Assim, compreendeu-se 
que características pessoais do terapeuta podem afetar o processo terapêutico e influenciá-lo quanto à sua efetividade. Considerando-se que se trata de uma relação de influência mútua, ambos podem atuar sobre o outro com diferentes funções. A construção de uma aliança terapêutica atua como importante veículo para a condução das mudanças comportamentais do cliente e requer do terapeuta uma vasta gama de habilidades (Meyer e Vermes, 2001).

Além de estar sob controle das contingências presentes no momento da sessão, bem como, de seu arcabouço teórico-metodológico, o terapeuta, por sua vez, também tem seu comportamento controlado por seus valores e emoções, determinados pelas contingências vividas em sua história pessoal (Guilhardi, 2001). Banaco (1993) também afirma que os sentimentos e pensamentos do terapeuta podem gerar interferência no processo terapêutico sendo necessário ao terapeuta estar consciente dos mesmos, evitando prejuízos para processo e relação terapêutica. Assim, o autoconhecimento do terapeuta torna-se elemento indispensável para o processo terapêutico, uma vez que permite maior clareza e conhecimento da forma como estes fatores estão interferindo no processo, tendo a supervisão um papel fundamental para isso (Banaco, 1993).

Geralmente, o primeiro atendimento desperta sentimentos diversos nos terapeutas iniciantes, sendo a ansiedade um sentimento preponderante e muito relatado no início dos atendimentos na clínica psicológica. Banaco (1993) aponta que atender é uma classe de repostas que ainda não faz parte do repertório comportamental do terapeuta iniciante. Este o faz sob controle de regras do supervisor. Como este comportamento ainda não foi diretamente modelado, é incipiente, não sendo emitido de forma consistente na sessão. Além disso, as pressões para um bom desempenho podem gerar no terapeuta comportamentos de fuga-esquiva de possíveis críticas e más avaliações, por parte do supervisor, grupo de supervisão ou do próprio cliente. Comportar-se de forma a minimizar os confrontos e agradar o cliente durante o atendimento pode ser uma alternativa para manter o cliente em terapia e evitar punições por parte do próprio cliente, bem como, do supervisor.

Falcone (2006) aponta ser comum a psicoterapia se tornar um agente estressante para os terapeutas, em especial para os terapeutas mais jovens, apesar de também afetar os mais experientes. Entre os fatores indicados pela autora, constam, dentre outros, fatores relativos aos comportamentos dos clientes. Entre os comportamentos apontados pela autora como mais 
estressantes aos psicoterapeutas, destacam-se: pensamentos suicidas de seus pacientes, casos de depressão, dependência emocional do paciente em relação ao terapeuta, transtornos psiquiátricos, comportamentos agressivos e hostis. Trata-se de padrões que geralmente envolvem oposição às estratégias terapêuticas ou que dificultam o envolvimento do cliente no processo.

Considerando a complexidade que compõe a atuação do terapeuta, as múltiplas variáveis de controle que o afetam e as habilidades terapêuticas que dele são requeridas, a supervisão de atendimentos em psicologia clínica é um recurso pedagógico fundamental para o treinamento e aperfeiçoamento de habilidades terapêuticas em graduandos em formação. Castanheira (2002) afirma que o ensino destas habilidades vai além do emprego de técnicas e teorias, exigindo análise de comportamentos públicos e encobertos do terapeuta, bem como, a instalação de habilidades pessoais durante a supervisão. A autora descreve um conjunto diversificado de habilidades que devem compor 0 repertório durante o atendimento, que variam de respostas simples, como chamar o cliente pelo nome, a respostas complexas e subjetivas, como ter equilíbrio emocional.

De acordo com Vandenberghe (2001), nos estágios em supervisão, deve ser analisado o repertório do terapeuta em formação, de tal forma que seus comportamentos verbais de relato da interação com o cliente sejam modelados e as regras e modelos fornecidos em supervisão possam afetar e contribuir para o desempenho do terapeuta em formação na prática interventiva. Além disso, faz parte dessa análise, os comportamentos encobertos do terapeuta, para que se possam identificar pistas da relação estabelecida entre cliente e terapeuta e assim modificar esta relação quando necessário. Desta maneira, a supervisão assume um caráter quase terapêutico para o profissional em formação.

Frente a essas condições, o supervisor tem o duplo papel, a saber:

a) zelar pelo atendimento adequado e de qualidade prestado ao cliente, processo nomeado por Vandenberghe (2001) como "terapia por mediador", em que são apresentadas as regras para o supervisionado agir frente às ações do cliente visando assim, à prestação de atendimento ao cliente;

b) instalar e modelar repertórios no terapeuta relativos a estabelecimento de vínculos, empatia, análises, confrontação, entre tantas outras habilidades requeridas pelo processo terapêutico. 
Diante disso, o presente trabalho se propõe a compartilhar uma experiência ocorrida ao longo de uma supervisão em Psicologia Clínica Comportamental. Os desafios para a aprendizagem e aquisição de conhecimentos práticos e habilidades terapêuticas foram intensificados neste caso em função do primeiro cliente da terapeuta em formação apresentar um perfil agressivo, tornando a condição de atendimento altamente aversiva para a terapeuta.

\section{MÉTODO}

As supervisões do caso clínico eram realizadas semanalmente nas dependências de uma Clínica Escola de uma Instituição de Ensino Superior, sem fins lucrativos de caráter comunitário, onde os atendimentos eram realizados com o cliente em uma sala individual. As supervisões eram em grupos de cinco alunos, sendo todos alunos do último ano do curso de Psicologia. Os terapeutas em formação relatavam seus casos, analisavam com base no modelo de Análise Funcional e planejavam as sessões subsequentes com o auxílio da supervisora e demais participantes do grupo. Os clientes atendidos declararam ciência e autorizaram a gravação das sessões, bem como, a discussão do caso em grupos de supervisão e a publicação dos dados para fins acadêmicos.

\section{RESULTADOS E DISCUSSÃO}

O relato do cliente nas primeiras sessões foi de episódios de agressividade por parte dele, em que descrevia brigas e ameaças feitas a outras pessoas. Foram selecionadas algumas falas para ilustrar os padrões do cliente (C):

C: "Eu quase bati nela, eu não bati porque um amigo segurou minha mão e me tirou de lá".

C: "Quando alguém resolve me tratar mal vou responder à altura ou maior, não me preocupo com o resultado que vai dar depois".

C: "Eu fiquei nervoso, chutei um vaso e quebrei o meu pé".

Em diferentes oportunidades desqualificou os conhecimentos da terapeuta referindo-se ao fato dela ser muito nova e despreparada para o atendimento, considerando que ainda era uma aluna. O cliente emitia verbalizações como:

C: "Pergunta para sua supervisora o que você deve fazer e na próxima sessão a gente volta a conversar!".

C: "Eu já até pensei em fazer Psicologia, sei como são essas coisas de tentar analisar o paciente, eu sei o que você está tentando fazer comigo". 
C: "Eu diferencio bem as coisas, caso contrário no primeiro dia você já estava morta".

O padrão comportamental apresentado pelo cliente, no início do processo terapêutico, gerou alguns efeitos, tanto operantes como respondentes na terapeuta, que foram identificados em supervisão. Alguns desses efeitos foram analisados como problemáticos para o processo terapêutico, dentre eles:

a) Esquivas da terapeuta de abordar assuntos que desagradassem o cliente;

b) Controle da sessão pelo cliente;

c) Respondentes de ansiedade da terapeuta; nos atendimentos e na própria supervisão sendo a ruborização da face e sudorese os respondentes observáveis.

d) Relato verbal da terapeuta de esquiva ao cliente: "Confesso que torci pra ele faltar essa semana".

A terapeuta em formação experimentava sentimentos e se comportava na sessão a partir das relações coercitivas estabelecidas pelo cliente. Como comportamentos da terapeuta produzidos por esta relação podem-se destacar comportamentos de fuga-esquiva dos atendimentos ou de situações que gerassem confronto e desacordo com o cliente. O cliente apresentava um padrão, destacado por Falcone (2006), como um agente estressor para terapeutas em geral: a agressividade. Além das condições aversivas já presentes no início do processo para maioria dos terapeutas em formação e as dificuldades intrínsecas à condição de exigência de um repertório ainda não adquirido, esta situação agravara-se pelo fato da relação com o cliente em si mesma também apresentar componentes aversivos. Frente a essas condições, além da análise funcional do caso do cliente e orientações gerais para a condução, cuidados adicionais foram necessários a este processo de supervisão.

O papel do supervisor, em si mesmo, também representa socialmente uma figura de controle excessivo e geralmente aversivo, gerando alta probabilidade dos alunos emitirem comportamentos de fuga esquiva de punições como críticas e reprovações. Sendo assim, acolhimento e expressões de empatia da supervisora à terapeuta em formação foram estratégias adotadas com o objetivo de amenizar os sentimentos aversivos da terapeuta em relação ao caso. Ser uma audiência não punitiva é uma condição fundamental explicitada por Skinner (2003) para que o cliente não apresente comportamentos fuga-esquiva do processo. Aponta ainda, que inicialmente o terapeuta representa para o cliente mais uma pessoa a exercer controle sobre seu comportamento, cabendo ao 
terapeuta agir de forma diferenciada e adquirir nova função. O mesmo recurso foi adotado em supervisão. Os comportamentos de fuga-esquiva durante as supervisões poderiam ser emitidos sob a forma de ocultação de informações relevantes para o prosseguimento do caso e emissão de tatos impuros a respeito da sessão, ou seja, relatos mantidos sob controle de reforçadores específicos, e não dos estímulos discriminativos que deveriam descrever, como no caso de um tato puro. Assim, há um risco do terapeuta em formação se comportar sob controle do que pode gerar reforçadores sociais por parte do supervisor e não propriamente dos eventos ocorridos em sessão. Assim, a supervisora (S), de forma análoga a um terapeuta em sessão, emitia respostas de acolhimento e empatia à terapeuta em formação $(T)$, como no exemplo:

S.: "Sei que não é fácil, T. Já é difícil o primeiro cliente, todos já ficam ansiosos nessa condição, com um caso como o dele então, sei que está mais difícil pra você, mas calma, você está fazendo o que é possível por enquanto e eu estou aqui justamente para ajudá-la".

Em supervisão também eram realizadas análises funcionais do comportamento da própria terapeuta em sessão. A análise funcional representa, de acordo com Neno (2003), um modelo de interpretação e investigação de fenômenos naturais, condizente à proposta filosófica do Behaviorismo Radical. A partir da análise funcional, as variáveis de controle de um comportamento são explicitadas e permite-se então analisar a função de um determinado comportamento, adotando-se uma noção selecionista. Levantar as variáveis de controle de um comportamento a partir de perguntas ou descrições dessas variáveis pela comunidade verbal é também uma condição para o desenvolvimento de autoconhecimento (Skinner, 2004). Assim, realizar análise funcional do comportamento da terapeuta em sessão, durante a supervisão, além de ser um recurso para a terapeuta analisar as consequências de seus comportamentos para o processo terapêutico, ainda favorece o desenvolvimento de autoconhecimento, o que, para Skinner (2004) coloca a pessoa "em melhor posição de prever e controlar seu próprio comportamento" (p. 31). Análises funcionais do comportamento da terapeuta podem ser ilustradas no seguinte trecho:

S.: "Quando você falou dos amigos dele hoje, ele mudou de assunto. E você, o que fez depois?". 
T.: "Ele acabou começando a contar uma história que não tinha nada a ver, e quando eu vi, entrei no assunto da história com ele".

S.: "Você está permitindo que ele se esquive. Sei que tem feito isso porque ele é muito agressivo e assim, sente medo das respostas dele e permite que ele se esquive, evitando assim um confronto na sessão. Mas isso é uma esquiva sua também. Se não mudar seu padrão com ele, não haverá ganhos no processo terapêutico, pois você agirá como mais uma pessoa da sua comunidade verbal, que se esquiva e foge dele."

Outro procedimento adotado em supervisão foi o de modelagem dos relatos verbais da terapeuta de analisar e impedir esquivas do cliente. Kohlenberg e Tsai (2006) afirmam que o bloqueio da esquiva é uma estratégia necessária quando os comportamentos de esquiva do cliente impedem o desenvolvimento de repertórios mais efetivos. Todavia, chamam a atenção que ao bloquear a esquiva do cliente aumenta-se o contato com as contingências aversivas das quais o cliente está se esquivando, tornando o processo aversivo ao cliente. Assim, o bloqueio de esquiva requer uma relação terapêutica bem estabelecida, em que a disponibilidade de outros reforçadores na sessão concorra com estes eventos aversivos e mantenha o cliente em terapia. Considerando o padrão agressivo do cliente, a terapeuta apresentava tendências de fugir e se esquivar desses procedimentos, evitando uma resposta de contracontrole por parte do cliente. Assim, em supervisão, a terapeuta era socialmente muito reforçada pela supervisora e colegas do grupo quando se expunha a esses procedimentos, na tentativa de gerar contingências reforçadoras que concorressem com a ameaça de controle aversivo presentes na sessão.

S.: "Que bom... T. Você conseguiu segurá-lo no assunto, não deixou que ele fugisse como sempre faz. Você deve ter se sentido mais segura mantendo o domínio da sessão".

S.: "Se você disser isso pra ele, vai ser uma agressão pra ele, muito punitivo, há um risco grande dele se irritar e gerar um problema na sessão. Vamos lá, como você poderia falar isso de outra forma?".

S.: Ufa, estou aliviada, muito feliz que você tenha conseguido falar tudo isso pra ele. Estava difícil você criar coragem, mas nessa sessão foi... E você viu como ele reagiu bem? É só casca T., panca de durão, no fim ele te ouviu e aceitou. Mas isso porque você foi precisa, delicada e clara, e não deixou saída pra ele... Estou muito aliviada e orgulhosa de você. 
As mudanças do cliente frente ao procedimento adotado pela terapeuta foram contingências naturalmente reforçadoras que certamente favoreceram a manutenção e refinamento dos comportamentos da terapeuta em sessão, minimizando suas esquivas desse tipo de intervenção.

A modelação também foi um recurso necessário em supervisão. A supervisora dava modelos claros de como a terapeuta poderia interagir com o cliente nos momentos mais críticos do processo. Conforme Banaco (1993), considerando que o padrão de atender ainda não é parte do repertório do terapeuta, há a necessidade do predomínio de regras e modelos para controlar o comportamento da terapeuta até que as contingências naturais do atendimento e da supervisão selecionem um padrão mais hábil por parte do terapeuta. Alguns exemplos de regras e modelos podem ilustrar as estratégias adotadas em supervisão:

S.: Vamos lá T., vamos ser mais firmes (...). Se perguntar como ele acha que o outro se sentiu, ele vai dizer que normal, que entendeu etc. Então você é que tem que se antecipar e já descrever pra ele: Eu acho, eu acho não, tenho certeza que ele ficou muito bravo com você!

S.: "T. sinaliza isso de forma explícita... Caras e bocas oh: Nossa C. você falou isso?".

Castanheira (2003) enfatiza que inicialmente o terapeuta em formação responde por regras descritas pelo supervisor e ao passo em que vai se expondo aos atendimentos subsequentes, consequências naturais de seus comportamentos em sessão selecionam um padrão mais refinado de interação com o cliente. Assim, além dos reforçadores sociais programados em supervisão, os reforçadores naturais do atendimento, ou seja, as mudanças do cliente adquiriram função reforçadora, controlando o comportamento da terapeuta. Como resultado desse processo de supervisão e da exposição contínua às sessões de atendimento, houve extinção de padrões agressivos ou hostis do cliente dirigidos à terapeuta. Esses comportamentos não tiveram consequências ou foram punidos de forma branda. A terapeuta encorajou-se para consequenciar o cliente e analisar funcionalmente os seus comportamentos problema sem necessidade de treino explícito ou modelos fornecidos em supervisão, como nos exemplos de interação entre terapeuta e cliente:

C: Você não viu o que eu escrevi pra você [no facebook]? 
T: "Vi. (silêncio). Não respondi por que o face é para meu uso pessoal, prefiro não misturar as coisas. Além disso, o comentário foi um pouco ofensivo, então preferi nem responder".

Em outra situação:

T: C. você já parou para pensar que esse tipo de comportamento pode influenciar o afastamento deles? (...). Aqui pra mim você relata com uma hostilidade tão grande, que eu não o imagino falando de outra forma para a sua mãe, ainda mais diante de tudo o que aconteceu. (...). Essa hostilidade já é algo tão natural que você não percebe, e isso só vai dificultando a relação entre você e sua família.

Frente às mudanças da terapeuta, houve avanços no processo terapêutico para o cliente, que passou a ficar mais sensível às consequências de suas ações, como ilustrado nestas falas do cliente:

C.: "Eu falei pra ele vir me visitar mais vezes, que era muito bom conversar com ele".

C.: "Agora eu sempre chego lá falo bom dia, brinco e tal, esses dias eu levei uma caixa de bombom pra dar uma animada nas meninas".

A aluna desenvolveu sentimentos mais positivos em relação ao cliente e diminuíram os comportamentos respondentes observados em supervisão, bem como, os comportamentos de fuga e esquiva em relação aos atendimentos. A terapeuta chegou a utilizar os dados do seu atendimento para produzir sua monografia da graduação, o que gerou diversos elogios da banca sobre a condução e análise do caso.

Os progressos do cliente no processo terapêutico, a diminuição do controle aversivo por ele estabelecido, os elogios da supervisora e grupo de supervisão, e ainda, os elogios da banca na apresentação da monografia sobre o tema foram variáveis fundamentais para o desenvolvimento do sentimento de autoconfiança da terapeuta em formação em relação aos atendimentos. O sentimento de autoconfiança, de acordo com Guilhardi (2002) é produto de consequências reforçadoras produzidas por desempenho. A terapeuta teve como consequência reforçadora contingente ao seu desempenho as mudanças de comportamento do cliente, bem como o reconhecimento social de todo o grupo. O sentimento de autoconfiança pode ser identificado na fala da aluna: "Depois de um caso como este, me sinto mais preparada para atender qualquer caso". 


\section{CONSIDERAÇÕES FINAIS}

Semelhante ao processo terapêutico, a supervisão exerce função de desenvolvimento de habilidades e ampliação de repertório do terapeuta em formação para acesso a contingências reforçadoras e diminuição da exposição a contingências aversivas. Para isso, a supervisão também requer a descrição de contingências sob forma de análise funcional do comportamento do próprio terapeuta no enfrentamento das contingências presentes na sessão, aumentando o autoconhecimento do terapeuta do seu repertório comportamental, excessos, déficits e sentimentos. Trata-se de um processo tão complexo quanto à própria terapia, que pode evocar respostas novas nos terapeutas em formação e eliciar diferentes sentimentos.

Diante da complexidade do contexto de supervisão, são requeridas do supervisor habilidades também semelhantes às apresentadas no contexto terapêutico: empatia, acolhimento, disposição para análises funcionais imediatas, fornecimento de feedbacks claros, de modelos e regras para o terapeuta em formação. Para aumentar as chances de sucesso, tanto do desenvolvimento de habilidades do terapeuta, quanto do cliente que está sendo por ele atendido, o estabelecimento de um vínculo entre supervisor e terapeuta é fundamental para que todas as estratégias adotadas tenham as funções pretendidas sobre o comportamento do terapeuta. Trata-se de um duplo desafio ao supervisor de fornecer um bom atendimento ao cliente, razão de todo o processo de formação, bem como para o terapeuta, que mesmo sem uma decisão deliberada sobre isso, também se submete à análise.

\section{REFERÊNCIAS}

Banaco, R. A. (1993). O impacto do atendimento sobre a pessoa do terapeuta. Temas em Psicologia, 2, 71-79.

Braga, G. L. B. \& Vandenberghe, L. (2006). Abrangência e função da relação terapêutica na terapia comportamental. Estudos de Psicologia, 23(3), 307314.

Castanheira, S. S. (2002). O primeiro cliente a gente nunca esquece. In H. J. Guilhardi, M. B. B. P. Madi, P. P. Queiroz \& M. C. Scoz (Orgs.), Sobre comportamento e cognição: Contribuições para a construção da teoria do comportamento (pp.357-366). Santo André: ESETec. 
Falcone, E. M. O. (2006). A dor e a delícia de ser um terapeuta: Considerações sobre o impacto da psicoterapia na pessoa do profissional de ajuda. In $\mathrm{H}$. J. Guilhardi, \& N. C. Aguirre (Orgs.), Sobre comportamento e cognição: Expondo a variabilidade (pp.135-145). Santo André: ESETec Editores Associados.

Guilhardi, H. J. (2001). Com que contingências o terapeuta trabalha em sua atuação clínica? In R. A. Banaco (Org.), Sobre comportamento e cognição: Aspectos teóricos, metodológicos e de formação em análise do comportamento e terapia cognitivista. (pp.316-331). Santo André: ESETec Editores Associados.

Guilhardi, H. J. (2002). Autoestima, autoconfiança e responsabilidade. In M. Z. Brandão, F. S. C Conte \& S. M. B. Mezzaroba (Orgs), Comportamento humano: Tudo (ou quase tudo) que você precisa saber para viver melhor (pp. 66-98). Santo André: ESETec Editores Associados.

Kohlenberg, R. J. \& Tsai, M. (2006) Psicoterapia analítica funcional: Criando relações terapêuticas intensas e curativas. Santo André: ESETec Editores Associados.

Meyer, S. \& Vermes, J. S. (2001). Relação terapêutica. In B. Rangé. Psicoterapias cognitivo-comportamentais: Um diálogo com a psiquiatria. Porto Alegre: Artmed.

Neno, S. (2003) Análise funcional: Definição e aplicação na terapia analíticocomportamental Revista Brasileira de Terapia Comportamental e Cognitiva, 5(2), 151-165.

Silveira, J. M. \& Kerbauy, R. R. (2000). A interação terapêutica: Uma investigação com base na queixa clínica. In R. Kerbauy (Org), Sobre comportamento e cognição (Vol. 5, pp. 213-221). Santo André: ESETec.

Skinner, B. F. (2003). Ciência e comportamento humano. São Paulo: Martins Fontes. (Original publicado em 1953).

Skinner, B. F. (2004). Sobre o behaviorismo. São Paulo: Cultrix. (Original publicado em 1974).

Vandenberghe, L. (1997). Uma abordagem contextual para supervisão clínica. In R. A. Banaco (Org.), Sobre comportamento e cognição: Aspectos teóricos, metodológicos e de formação em análise do comportamento e teoria cognitivista (pp. 496-591). São Paulo: Arbytes. 
Velasco, S. M. \& Cirino, S. D. (2002). A relação terapêutica como foco da análise na prática clínica comportamental. In A. M. S. Teixeira; M. R. B. Assunção; R. R. Starling \& S. S. Castanheira (Orgs.), Ciência do comportamento: Conhecer e avançar (pp. 34-42). Santo André: ESETec.

Contato: ra_ms10@hotmail.com

Recebido em: 09/06/2014

Revisado em: 02/07/2014

Aceito em: 11/08/2014 